\title{
Hydrogen silsesquioxane mold coatings for improved replication of nanopatterns by injection molding
}

\author{
Hobæk, Thor Christian; Matschuk, Maria; Kafka, Jan ; Pranov, Henrik J.; Larsen, Niels Bent
}

Published in:

Journal of Micromechanics and Microengineering

Link to article, DOI:

$10.1088 / 0960-1317 / 25 / 3 / 035018$

Publication date:

2015

Document Version

Peer reviewed version

Link back to DTU Orbit

Citation (APA):

Hobæk, T. C., Matschuk, M., Kafka, J., Pranov, H. J., \& Larsen, N. B. (2015). Hydrogen silsesquioxane mold coatings for improved replication of nanopatterns by injection molding. Journal of Micromechanics and Microengineering, 25(3), 035018. https://doi.org/10.1088/0960-1317/25/3/035018

\section{General rights}

Copyright and moral rights for the publications made accessible in the public portal are retained by the authors and/or other copyright owners and it is a condition of accessing publications that users recognise and abide by the legal requirements associated with these rights.

- Users may download and print one copy of any publication from the public portal for the purpose of private study or research.

- You may not further distribute the material or use it for any profit-making activity or commercial gain

- You may freely distribute the URL identifying the publication in the public portal 


\title{
Hydrogen silsesquioxane (HSQ) mold coatings for improved
}

\section{replication of nanopatterns by injection molding}

\author{
Thor Christian Hobak ${ }^{1}$, Maria Matschuk ${ }^{2}$, Jan Kafka ${ }^{2}$, Henrik J. Pranov ${ }^{2}$ and Niels B. Larsen ${ }^{1}$ \\ ${ }^{1}$ Department of Micro- and Nanotechnology, Technical University of Denmark, Ørsteds Plads 345E, \\ 2800 Kgs. Lyngby, Denmark \\ ${ }^{2}$ InMold Biosystems, Diplomvej 381, 2800 Kgs. Lyngby, Denmark \\ E-mail: niels.b.larsen@nanotech.dtu.dk
}

\begin{abstract}
We demonstrate the replication of nanosized pillars in polymer (cyclic olefin copolymer) by injection molding using nanostructured thermally cured hydrogen silsesquioxane (HSQ) ceramic coatings on stainless steel mold inserts with mold nanostructures produced by a simple embossing process. At isothermal mold conditions, the average pillar height increases by up to $100 \%$ and a more uniform height distribution is observed compared to a traditional metal mold insert. Thermal heat transfer simulations predict that the HSQ film retards the cooling of the polymer melt during the initial stages of replication, thus allowing more time to fill the nanoscale cavities compared to standard metal molds. A monolayer of a fluorinated silane (FDTS) deposited on the mold surface reduces the mold/polymer interfacial energy to support demolding of the polymer replica. The mechanical stability of thermally cured HSQ makes it a promising material for nanopattern replication on an industrial scale without the need for slow and energy intensive variotherm processes.
\end{abstract}


Injection molding has been the preferred industrial process for polymer shaping for decades due to low cycle times and the multitude of technologies established for full process automation $[1,2]$. Considerable know-how and experience is established on replication on the macroscopic scale using this technique. During the last two decades this knowledge base has been extended to replication of micro- and nanoscale features. A wide range of applications has been explored including microfluidic devices [3,4], diffractive optical elements [5], anti-reflective surfaces [6,7], superhydrophobic surfaces [8-10], and functional cell culture substrates [11-14]. Commercial injection molding is routinely used to replicate features with details down to $150 \mathrm{~nm}$ in the case of Blu-Ray discs, while replication demonstrating lateral resolution as low as $5 \mathrm{~nm}$ has been demonstrated in research [15-20]. This suggests that the lower limit of replication is determined by the structural detail of the mold surface.

Replication of nanoscale features is more challenging when targeting height-to-width aspect ratio above 1. A limiting factor in the replication of higher aspect ratio structures is the rapid formation of a solidified skin layer after the hot polymer melt contacts the cold mold surface [21] resulting in a significant increase in the flow resistance inside micro- and nano-scale cavities due to the high viscosity. A general strategy for improving replication of high aspect-ratio features is to increase the melt and mold temperature as well as the injection speed, which reduces the thickness of the skin layer formed prior to filling of the cavity. Additionally, high injection pressures also help to force the melt into cavities even after skin formation $[19,20,22,23]$.

The most important factor for achieving good replication is generally agreed to be the mold temperature, $T_{\mathrm{m}},[16,19,22]$ that often needs to be above the glass-transition temperature, $T_{\mathrm{g}}$, of the polymer for replicating high aspect ratio structures [24,25]. This calls for the use of a "variotherm" process, i.e. active heating and cooling of the mold for each replication cycle. The main disadvantage is longer process cycle times: While conventional injection molding uses cycle times from 1-30 s, variotherm processes may require $100-300 \mathrm{~s}$ for each replication when accurate thermal control is required [24]. The repeated thermal cycling can also lead to lower mold lifetime due to thermal stresses [25], as well as higher energy consumption, which both contribute to overall higher production costs.

Several authors have reported on methods to reduce the thermal cycling time for variotherm processes and a number of such methods has been commercialized. Advanced mold designs and manipulators have been developed to reduce the cycle time below $30 \mathrm{~s}$ at the price of more complex and expensive mold fabrication methods and less thermal control of the mold surface. These involves heating of the stamper material itself by electrical (Joule heating) [26-28] or induction heating [29,30]. Other methods involve external heating of the stamper surface, such as infrared heating $[31,32]$ or steam heating [33]. Laser-heating of the mold has been used to achieve extremely rapid mold heating $\left(300{ }^{\circ} \mathrm{C} / \mathrm{s}\right)$ [34], although the heated area is rather small and with a spatially inhomogeneous temperature. Several of these methods have demonstrated cycle times comparable to conventional 
injection molding, but they add complexity to the mold and the machine, making it more expensive to set up and maintain a production line.

A simpler alternative to variotherm processes involves the use of heat retarding materials to impede the heat transfer from the hot polymer melt to the cold mold. Nickel shims formed by electroplating from a metallized silicon master have become the standard insert material for microand nano-replication, due to its ease of replication and good durability [3,5]. Nickel has a high thermal conductivity, like most other metals, which leads to fast heat dissipation from the polymer melt during mold filling and rapid formation of a solidified polymer skin layer. Adding a heat-insulating plate on the backside of a nickel shim has been shown to slow the heat transfer resulting in increased replication quality [35,36]. Likewise, a polymer foil covering one of the mold halves allowed fabrication of high-aspect ratio microcantilevers through an isothermal process [37]. Furthermore, polymeric stampers with imprinted micro- [38] and nano-structures [39] showed improved filling at low mold temperatures compared to a nickel stamper. Although these examples demonstrated impressive replication without the need for a variotherm process, they are likely not suitable for highvolume production as the mold materials used lack the mechanical durability that is required in an industrial setting.

Here, we demonstrate the improved filling of nanostructures using a hybrid mold consisting of a film of hydrogen silsesquioxane (HSQ) with imprinted nanostructures on a stainless steel mold. HSQ is a soluble organosilicon compound that forms hard cross-linked molecular networks upon thermal curing. HSQ thin films are established in commercial integrated circuit production as a precursor for interlayer dielectrics [40] and as an electron-beam resist with lateral resolution down to $5 \mathrm{~nm}$ [41]. For polymer shaping, structured HSQ films on silicon have previously been used as stamps for nanoscale features by hot embossing $[42,43]$. Heat treated HSQ forms a silica-like material that easily reacts with silane-based chemistry employed for applying anti-stiction coatings to the stamp for improved release of polymer replicas [7,19,20,44]. In addition, planar HSQ films have been used as a surface coating on steel molds to lower the surface roughness [45] and we have recently observed an injection molding lifetime of at least 100000 cycles without measurable wear or defect formation in planar HSQ films of micrometer scale thickness on steel molds (unpublished data). Here, we show an improved filling of nanoscale holes using heat treated nanopatterned HSQ films under isothermal mold conditions compared to an all-metal electroplated nickel shim with an outer chromium/gold coating. Finite element modeling of the heat transfer between polymer melt and mold shows that the HSQ layer significantly retards the cooling after thermal contact between the materials is established, thus enabling improved nanoscale replication. 


\subsection{Mold insert fabrication}

\subsubsection{Silicon master fabrication}

The pattern used in this study, consisting of $370 \mathrm{~nm}$ wide and $400 \mathrm{~nm}$ high pillars arranged in a square grid of pitch $1000 \mathrm{~nm}$, was defined in a silicon (Si) master by deep-UV (DUV) stepper lithography. The dimensions of the structured area was $5.5 \times 5.5 \mathrm{~mm}^{2}$. Upscaling to larger areas by stitching multiple exposure fields is easily achieved by the stepper technology: The system employed is capable of exposing a full $\varnothing 200 \mathrm{~mm}$ wafer in less than a minute with a lateral resolution better than $250 \mathrm{~nm}$. First, a $60 \mathrm{~nm}$ thick bottom anti-reflective coating (DUV42P-6, Brewer Science, MO) was spin-coated to minimize interference effects and to promote adhesion. A $350 \mathrm{~nm}$ thick positive photoresist (JSR-M230Y, JSR Corporation, Japan) was spin-coated and baked at $130{ }^{\circ} \mathrm{C}$ for $90 \mathrm{~s}$. The resist was exposed with a FPA-3000 EX4 stepper system (Canon, Japan) using a $248 \mathrm{~nm} \mathrm{KrF}$ illumination source producing a square grid of exposed areas with a pitch of $700 \mathrm{~nm}$. A post-exposure bake was employed at $130{ }^{\circ} \mathrm{C}$ for $60 \mathrm{~s}$ before development of the photoresist. Openings in the resist were transferred into the underlying silicon by reactive-ion etching (Pegasus, SPTS, UK) using continuous etching ( $38 \mathrm{sccm} \mathrm{SF}$ ) and deposition of a passivation layer $\left(75 \mathrm{sccm} \mathrm{C}_{4} \mathrm{~F}_{8}\right.$ ) at a pressure of $4 \mathrm{mTorr}$, a coil/platen power of $800 \mathrm{~W} / 40 \mathrm{~W}$, a temperature of $-20^{\circ} \mathrm{C}$, and a total process time of 180 s.

\subsubsection{Metal mold insert fabrication}

All-metal mold inserts resulted from electroplating on the reactive-ion etched Si master. A metal seed layer of $15 \mathrm{~nm} \mathrm{Cr}$ and $45 \mathrm{~nm}$ Au was deposited on the master structures by sputter-coating (CMS 18, Kurt J. Lesker Company, UK). Nickel electroplating proceeded in a nickel sulfamate bath operated at $56{ }^{\circ} \mathrm{C}$ and at $\mathrm{pH}$ 3.6-3.8 (Microform 200, Technotrans, Germany). The resulting Ni shim had a thickness of $330 \mu \mathrm{m}$. The Ni shim could not easily be separated from the master, so the Si wafer was fully dissolved in $28 \% \mathrm{w} / \mathrm{v}$ aqueous $\mathrm{KOH}$ at $90{ }^{\circ} \mathrm{C}$. The electroplated shim was cut out with a mechanical punching tool defining a circular perimeter with two flats for aligning the shim in the mold.

\subsubsection{HSQ/steel mold insert fabrication}

Stainless steel substrates with a thickness of $1 \mathrm{~mm}$ were cut out by milling to include alignment flats. The substrates were wet polished with a series of sandpaper with grit size P500, P800 and P1200 (Norton Abrasives, UK), followed by $\mathrm{Al}_{2} \mathrm{O}_{3}$ paper with $5 \mu \mathrm{m}$ and $0.3 \mu \mathrm{m}$ mean particle size (Laser Components, Germany). The substrates were cleaned with $1 \% \mathrm{v} / \mathrm{v}$ Triton X-100 in MilliQ water (Millipore, MA) at $60{ }^{\circ} \mathrm{C}$ for $1 \mathrm{~h}$, followed by a $10 \mathrm{~min}$ air plasma $(0.5 \mathrm{mbar}, 50 \mathrm{~W})$ treatment to reduce hydrocarbon contamination. HSQ (FOx-16, Dow Corning, MI) was deposited by spin-coating at $2000 \mathrm{rpm}$. The HSQ was subsequently imprinted with a nanostructured elastomer stamp originating 
from the same Si master pattern. Afterwards, the stamp was released and the HSQ/steel mold was thermally cured, first at $80{ }^{\circ} \mathrm{C}$ for $24 \mathrm{~h}$ to remove solvent and subsequently at $450{ }^{\circ} \mathrm{C}$ for $2 \mathrm{~h}$ to crosslink the HSQ. The chemical structure of the HSQ layer was investigated by Fourier-transform infrared spectroscopy (FTIR) before and after curing of a HSQ film spin coated on a silicon wafer substrate instead of stainless steel to enable higher quality transmission FTIR measurements. The results are presented in the supplementary material, Figure S1, and shows extensive conversion of the cagestructure of HSQ into a silicon oxide network structure after $2 \mathrm{~h}$ curing at $450{ }^{\circ} \mathrm{C}$ in an oxygencontaining atmosphere as expected from a prior study on HSQ curing [46]. The elastic modulus of the cured film was determined by nanomechanical indentation using an NX-20 (Park Systems, Suwon, South Korea) atomic force microscope (AFM) mounted with a diamond-tipped cantilever. Analysis of the loading/unloading force-distance curve proceeded as described in a former report on cured HSQ [47].

\subsubsection{Surface coating of mold inserts}

Both the metal and HSQ/steel mold inserts were coated with a monolayer of heptadecafluoro1,1,2,2-tetrahydrodecyltrichlorosilane (FDTS) by molecular vapor deposition (MVD 100, Applied Microstructures, CA) using a previously described process [44].

\subsection{Injection molding}

Polymer replicas were injection molded on a Victory 80/45 Tech injection molder (Engel, Austria), using TOPAS 8007-S04 (TOPAS Advanced Polymers, Germany) cyclic olefin copolymer (COC) with $T_{\mathrm{g}} \sim 78^{\circ} \mathrm{C}$. The molded polymer replicas were $50 \mathrm{~mm}$ circular discs with a thickness of $2.0 \mathrm{~mm}$. The metal mold inserts were installed in the mold with a $1.0 \mathrm{~mm}$ aluminum back plate, while the HSQ/steel inserts were installed with a $330 \mu \mathrm{m}$ Ni back plate. Thus, both assemblies had a total thickness of $1.33 \mathrm{~mm}$. A fan-gate with a thickness of $0.35 \mathrm{~mm}$ was employed at the entrance of the mold cavity. The parameters used for injection molding are summarized in table 1 . The mold temperature was varied from $40{ }^{\circ} \mathrm{C}$ to $70^{\circ} \mathrm{C}$ in random sequence to avoid systematic errors from the thermal history of the mold. The injection velocity used was the maximum achievable on the injection molding system. The stated pressures during injection $\left(P_{\text {inject }}\right)$ and holding phase $\left(P_{\text {hold }}\right)$ are the pressures applied by the piston. After each parameter change, at least 40 replicas were injection molded to achieve stable molding conditions before collecting replicas for structural analysis.

A minimum cycle time of $60.2 \mathrm{~s}$ was achieved at $T_{\text {mold }}=70^{\circ} \mathrm{C}$. Using shorter cooling times, the injection molded parts were still too soft for reliable demolding, especially around the comparatively thick sprue $(\varnothing 6.5 \mathrm{~mm})$, due to the bulk of the polymer still being above $T_{\mathrm{g}}$. Thermal simulations revealed that the center of the $2 \mathrm{~mm}$ thick disc also remained above $T_{\mathrm{g}}$ for $>20 \mathrm{~s}$ at $T_{\text {mold }}=70{ }^{\circ} \mathrm{C}$ (data not shown). At $T_{\text {mold }}=40^{\circ} \mathrm{C}$ the cycle time could be reduced to $31.6 \mathrm{~s}$, due to the faster cooling of the molded parts. However, to be able to make a direct comparison of replicas fabricated at different mold temperatures, the total cycle time was kept constant at $60 \mathrm{~s}$ in this study. Shorter cycle times at $T_{\text {mold }}$ 
close to $T_{\mathrm{g}}$ would be enabled by reducing at least one dimension of the sprue cross-section. Further reductions in cycle times could be achieved by exchanging the stainless steel inserts and bulk steel mold parts for metals of higher thermal conductivity such as hardened copper alloys at the cost of increased wear and more expensive mold fabrication.

Table 1. Injection molding conditions.

\begin{tabular}{ccccccccc}
\hline$T_{\text {mold }}\left({ }^{\circ} \mathrm{C}\right)$ & $T_{\text {melt }}\left({ }^{\circ} \mathrm{C}\right)$ & $V_{\text {inject }}\left(\mathrm{cm}^{3} / \mathrm{s}\right)$ & $P_{\text {inject }}($ bar $)$ & $P_{\text {hold }}($ bar $)$ & $t_{\text {fill }}(\mathrm{s})$ & $t_{\text {hold }}(\mathrm{s})$ & $t_{\text {cool }}(\mathrm{s})$ & $t_{\text {cycle }}(\mathrm{s})$ \\
\hline $40-70$ & 250 & 27 & 1300 & 800 & 0.15 & 10 & 29 & 60.2 \\
\hline
\end{tabular}

\subsection{Mold insert and replica characterization}

Scanning electron micrographs (SEM) of uncoated metal and HSQ/steel mold inserts were acquired on a Supra 40 VP microscope (Carl Zeiss, Germany) using $5 \mathrm{kV}$ acceleration potential. The HSQ film thickness was measured by optical reflectance at incidence angles of $0^{\circ}$ and $70^{\circ}$ using a FilmTek 4000 reflectometer (Scientific Computing International, CA).

The polymer replica surface topography was analyzed by AFM using BudgetSensor-300 cantilevers on an XE-150 (Park Systems, Korea) operating in intermittent contact mode. For each mold temperature, three individual samples were each scanned at three different positions, separated by at least $1 \mathrm{~mm}$. The image scan size was $5 \times 5 \mu \mathrm{m}^{2}(256 \times 256$ pixels) at a line rate of $0.5 \mathrm{~Hz}$. The scans were analyzed using the SPIP 6.2.8 software package (Image Metrology, Denmark).

Each pillar was analyzed as grains using height threshold detection. At least 300 pillars for each parameter set were included in the analysis. The background level, defined as the base area surrounding the pillars, was corrected with a $2^{\text {nd }}$ degree polynomial plane fit. Each of the 256 line profiles was then fitted individually with a linear curve (excluding the data above the threshold level). This method was the most reliable for producing a zero-level flat background. The maximum height value of each grain was recorded and used to quantify the degree of replication. The same method was applied to quantify the depth of the structures in the mold, only measuring the negative grain height instead.

\subsection{Initial contact temperature calculation and finite element modeling of heat transfer}

Finite element modeling of the polymer melt cooling was performed with the COMSOL Multiphysics 4.4 software package (COMSOL, Sweden) by numerically solving the one-dimensional heat equation:

$$
\begin{aligned}
& \frac{\partial T}{\partial t}-\alpha \frac{\partial^{2} T}{\partial x^{2}}=0 \\
& \alpha=\frac{k}{\rho c_{p}}
\end{aligned}
$$

where $T$ is the temperature, $\alpha$ the thermal diffusivity, $k$ the thermal conductivity, $\rho$ the mass density, and $c_{\mathrm{p}}$ the specific heat capacity at constant pressure. The initial contact temperature, $T$, between two 
semi-infinite bodies at temperature $T_{1}$ and $T_{2}$, respectively, can be calculated analytically from their thermal effusivities $e$ :

$$
\begin{gathered}
T=T_{1}+\left(T_{2}-T_{1}\right) \frac{e_{2}}{e_{2}+e_{1}} \\
e=\left(k \cdot \rho \cdot c_{p}\right)^{\frac{1}{2}}
\end{gathered}
$$

The material constants used for $\mathrm{Cr}, \mathrm{Au}, \mathrm{Ni}, \mathrm{HSQ}$, stainless steel, and COC [48] are shown in table 2, together with the calculated thermal diffusivities and thermal effusivities. Any temperaturedependence is neglected. The outer layer of the all-metal mold consists of $\sim 15 \mathrm{~nm} \mathrm{Cr}$ and $\sim 45 \mathrm{~nm} \mathrm{Au}$ on top of the bulk electroplated $\mathrm{Ni}$. In the numerical simulations, the othermost two layers were approximated by a single $100 \mathrm{~nm}$ thick Au layer, as the chromium layer is extremely thin and has similar thermal transport properties to gold (table 2). The temporal development of the temperature at the polymer surface was studied at a point probe, defined as being the center surface point of the polymer melt just before filling a $\varnothing 400 \mathrm{~nm}$ circular nanocavity in the mold as described below . Perfect thermal contact between the mold and the polymer melt was assumed, with $T_{\text {mold }}=70{ }^{\circ} \mathrm{C}$ and $T_{\text {melt }}=250{ }^{\circ} \mathrm{C}$ as initial temperatures. The initial mold temperature of $70{ }^{\circ} \mathrm{C}$ was maintained in the mold at a distance of $300 \mu \mathrm{m}$ from the mold/melt interface, and a symmetry plane was defined in the polymer melt at a distance of $1000 \mu \mathrm{m}$ from the mold/melt interface. No movement of material was included in the simulations, thus heat dissipation by viscous effects was not considered.

Table 2. Material constants used for heat transfer analysis

\begin{tabular}{llllll}
\hline & $\begin{array}{l}\text { Thermal } \\
\text { conductivity, } k \\
\left(\mathrm{~W} \cdot \mathrm{m}^{-1} \cdot \mathrm{K}^{-1}\right)\end{array}$ & $\begin{array}{l}\text { Heat capacity, } c_{p} \\
\left(\mathrm{~J} \cdot \mathrm{kg}^{-1} \mathrm{~K}^{-1}\right)\end{array}$ & $\begin{array}{l}\text { Density, } \rho \\
\left(\mathrm{kg} \cdot \mathrm{m}^{-3}\right)\end{array}$ & $\begin{array}{l}\text { Thermal } \\
\text { diffusivity, } \alpha \\
\left(\mathrm{m}^{2} \cdot \mathrm{s}^{-1}\right)\end{array}$ & $\begin{array}{l}\text { Thermal } \\
\text { effusivity, } e \\
\left(\mathrm{~W} \cdot \mathrm{s}^{1 / 2} \cdot \mathrm{m}^{-2} \cdot \mathrm{K}^{-1}\right)\end{array}$ \\
\hline $\mathrm{Cr}$ & 93.7 & 448 & 7150 & $2.92 \cdot 10^{-5}$ & $1.73 \cdot 10^{4}$ \\
\hline $\mathrm{Au}$ & 317 & 129 & 19300 & $1.27 \cdot 10^{-4}$ & $2.81 \cdot 10^{4}$ \\
\hline $\mathrm{Ni}$ & 90.7 & 445 & 8900 & $2.29 \cdot 10^{-5}$ & $1.90 \cdot 10^{4}$ \\
\hline $\mathrm{HSQ}$ & 0.15 & 730 & 1400 & $1.46 \cdot 10^{-7}$ & $3.92 \cdot 10^{2}$ \\
\hline Stainless steel & 16.2 & 500 & 8000 & $4.05 \cdot 10^{-6}$ & $8.05 \cdot 10^{3}$ \\
\hline COC & 0.21 & 2200 & 1003 & $9.51 \cdot 10^{-8}$ & $6.81 \cdot 10^{2}$ \\
\hline
\end{tabular}

\section{Results}

\subsection{HSQ significantly improves replication compared to pure metal at isothermal mold conditions}

The lower heat conductivity of HSQ was expected to retard the heat dissipation from the polymer melt to the mold and thus delay the formation of a solidified skin layer. Figure 1 shows SEM micrographs of (a) the all-metal mold insert fabricated by electroplating and (b) the HSQ/steel mold 
insert fabricated by imprinting the HSQ layer with a surface structured elastomer stamp. The structures in HSQ appear to have more rounded edges due to the different fabrication processes between the two molds. However, this was not expected to affect the replication quality significantly. Charging effects were observed during SEM imaging of the HSQ film due to its low electrical conductivity leading to reduced image contrast. The average HSQ film thickness in the patterned area was $\sim 500 \mathrm{~nm}$ as measured by optical reflectometry, and the elastic modulus of the cured HSQ layer was $27.9 \mathrm{GPa}$ as determined by nanoindentation analysis (supplementary figure S2).
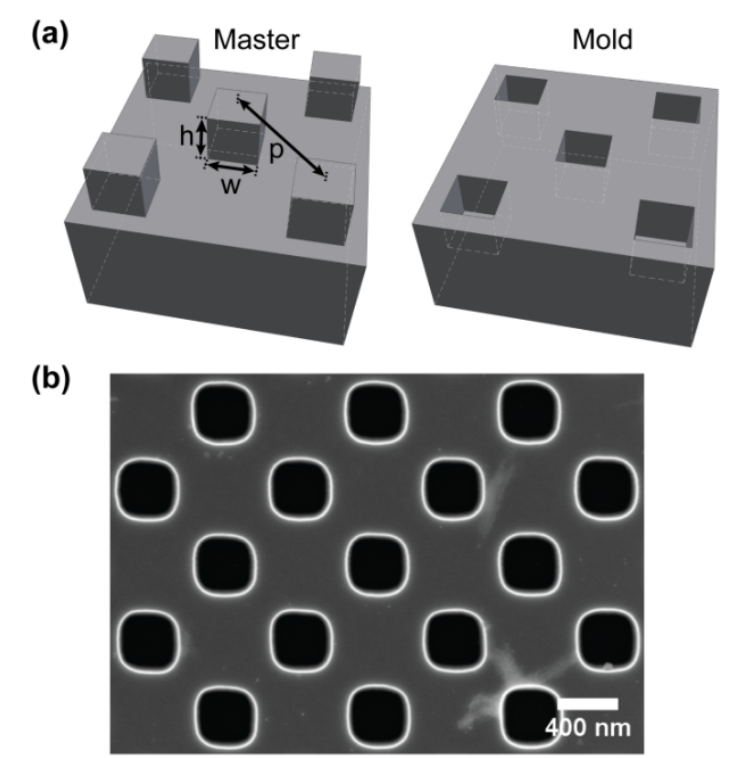

(c)

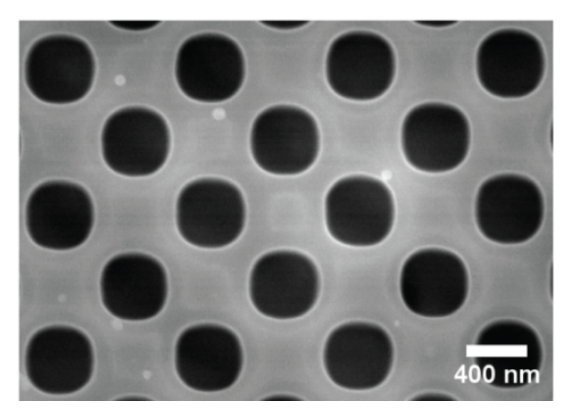

Figure 1. (a) Sketches of the master pillar structures and corresponding mold hole structures showing the height (h) and width (w) of the square master pillars as well as the pitch (p) of the square grid of pillars. SEM micrographs of hole arrays in (b) the all-metal mold and (c) the HSQ/steel mold insert.

Figure 2 displays AFM micrographs of polymer replicas injection molded against the structured mold inserts at different mold temperatures. The micrographs show that the mean pillar height increases monotonically with increasing mold temperature and is generally higher for HSQ than for an all-metal mold surface. The replicated structures appear to be wider for HSQ molds, although this is likely an artefact caused by AFM tip convolution. Injection molding with an all-metal insert at mold temperatures $\leq 60{ }^{\circ} \mathrm{C}$ leads to a spatially inhomogeneous distribution of pillar heights over the scan area and with some features not being replicated at all. Replicas from the HSQ/steel mold insert also shows some pillar height variations but to a much smaller extent and only at lower mold temperatures. 


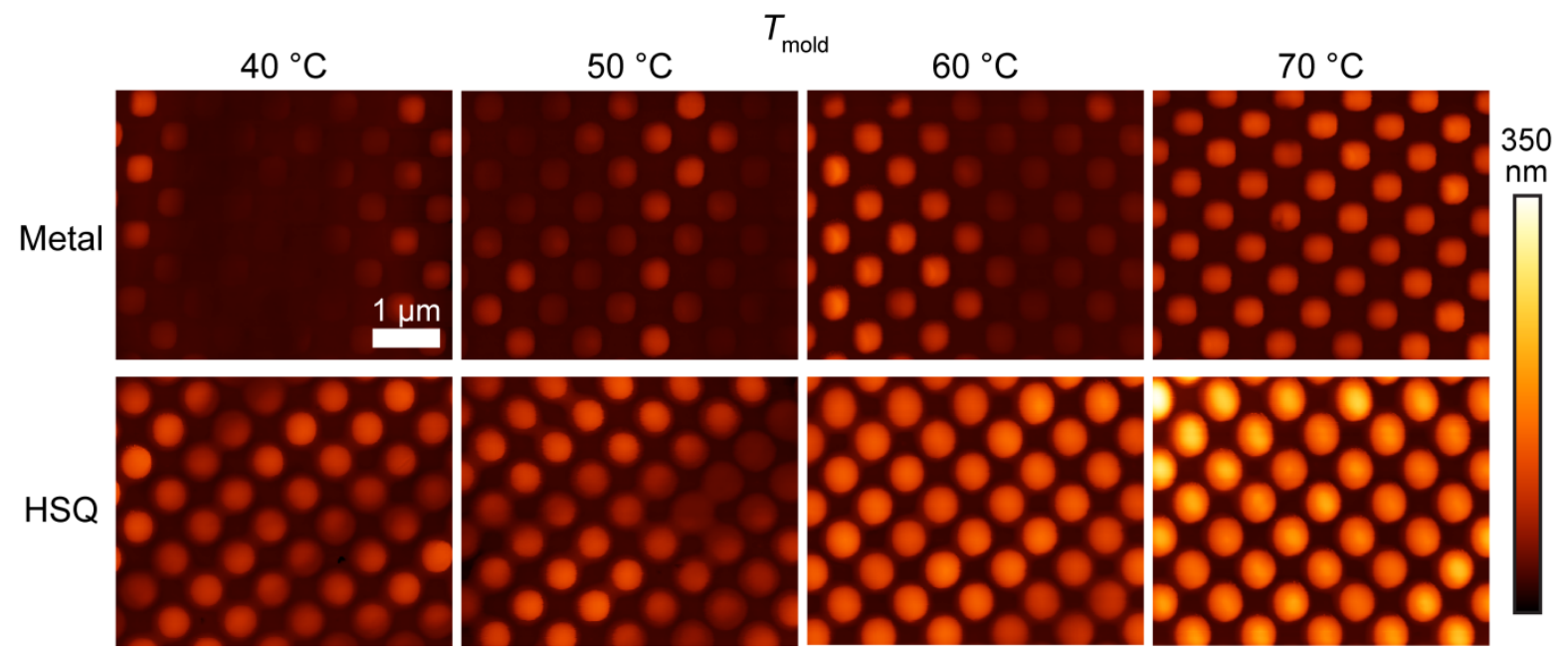

Figure 2. AFM micrographs of polymer replicas injection molded on an all-metal mold insert (upper row) or a HSQ/steel mold insert (lower row) at different mold temperatures. The displayed scan areas are $5 \times 4 \mu^{2}$ and the color height scale is $350 \mathrm{~nm}$.

The replication was quantified and is plotted in figure 3 for all-metal and HSQ/steel mold inserts based on height measurements of at least 300 replicated pillars from 3 individual samples, at each mold temperature. These measurements confirm that structured HSQ molds result in better replication than all-metal molds at all mold temperatures, as visually apparent in figure 2 . At mold temperatures of $40{ }^{\circ} \mathrm{C}$ and $50{ }^{\circ} \mathrm{C}$, i.e. $\sim 40{ }^{\circ} \mathrm{C}$ and $\sim 30{ }^{\circ} \mathrm{C}$ lower than the polymer $T_{\mathrm{g}}$, the mean replicated pillar height is increased by $100 \%$ compared to the all-metal mold, while the improvement at $70{ }^{\circ} \mathrm{C}$, close to $T_{\mathrm{g}}$, is $50 \%$. Full replication is still not achieved at this temperature as the HSQ hole structures (figure 1b) have a mean depth of $326 \mathrm{~nm}$ as determined by AFM (data not shown).

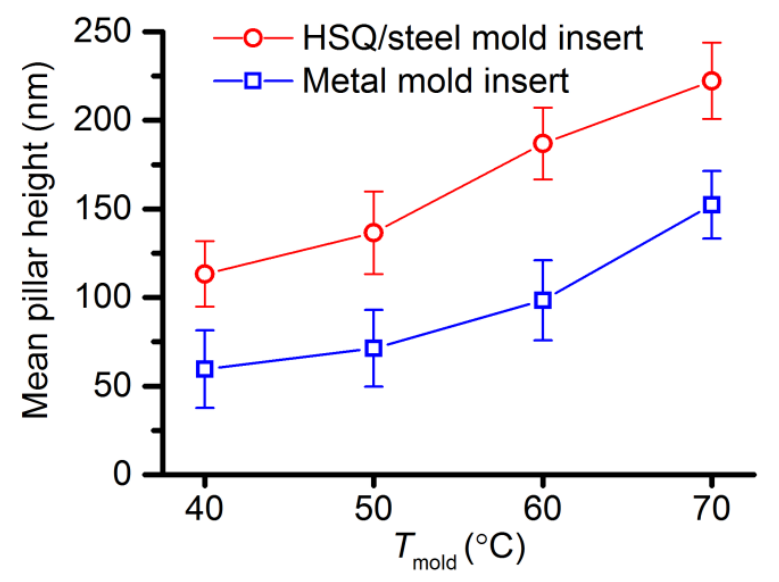

Figure 3. Mean pillar height of polymer replicas from structured all-metal and HSQ/steel mold inserts at various mold temperatures. The mean depth of the mold structures are $398 \mathrm{~nm}$ and $326 \mathrm{~nm}$ for the metal mold insert and the HSQ/steel mold insert, respectively. Error bars show the standard error of the mean $(n=3)$. 
Table 3 shows the calculated coefficient of variation (CV) of the pillar height defined as the ratio of the standard deviation to the mean. These data confirm a more homogeneous pillar replication with the HSQ/steel mold insert than with the all-metal mold insert at all mold temperatures and especially at the lower temperatures investigated. The HSQ/steel mold inserts were used during 900 injection molding cycles in this study, without any observable damage to the surface when visualized by SEM (data not shown).

Table 3. Coefficient of variation (\%) of the replicated pillars

\begin{tabular}{lcccc}
\cline { 2 - 4 } & \multicolumn{4}{c}{$T_{\text {mold }}$} \\
\cline { 2 - 5 } & $40{ }^{\circ} \mathrm{C}$ & $50{ }^{\circ} \mathrm{C}$ & $60{ }^{\circ} \mathrm{C}$ & $70{ }^{\circ} \mathrm{C}$ \\
\hline Metal mold insert & $64 \%$ & $53 \%$ & $40 \%$ & $22 \%$ \\
HSQ/steel mold insert & $28 \%$ & $30 \%$ & $19 \%$ & $17 \%$ \\
\hline
\end{tabular}

\subsection{Heat transfer simulations confirm heat retardation by HSQ}

The initial contact temperature between the COC polymer melt and the mold surface can be calculated using equation 3. The results for initial temperatures $T_{\text {mold }}=70{ }^{\circ} \mathrm{C}$ and $T_{\text {melt }}=250{ }^{\circ} \mathrm{C}$ are $77^{\circ} \mathrm{C}$ for $\mathrm{COC} / \mathrm{Cr}$ and $184{ }^{\circ} \mathrm{C}$ for $\mathrm{COC} / \mathrm{HSQ}$, which gives a first indication that HSQ may support sustained polymer flow after initial contact. Finite element modeling (FEM) of the cooling of the polymer melt immediately above a mold nanocavity is shown in figure 4 for an all-metal mold insert and a stainless steel mold insert as shown in the upper part of figure 5. The metal mold insert is modeled as consisting of a $100 \mathrm{~nm}$ thick Au layer on a nickel support, thus disregarding the minute influences expected from having a $\mathrm{Cr} / \mathrm{Au}$ layer instead of pure gold on the actual metal mold used for injection molding. The temperature probe point is on the rotational symmary axes shown in figure 5 at axial position $\mathrm{x}=0$. Upon thermal contact with the metal mold insert, the polymer melt cools rapidly from an initial temperature of $250{ }^{\circ} \mathrm{C}$ and reaches $T_{\mathrm{g}}$ after only $100 \mu \mathrm{s}$. In contrast, the polymer melt remains at temperatures above $T_{\mathrm{g}}$ for $>10 \mathrm{~ms}$ when contacting the HSQ/steel mold surface, i.e. at least 2 orders of magnitude longer. 


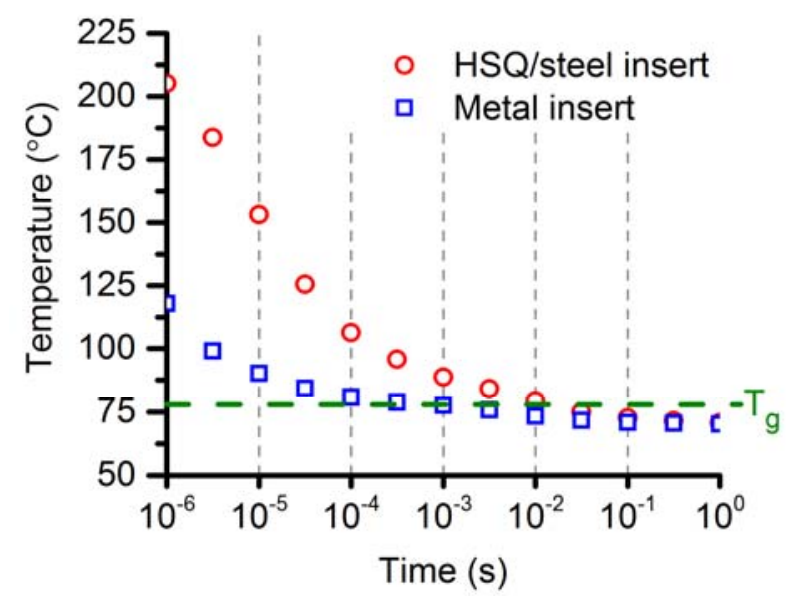

Figure 4. Finite element modeling of polymer melt cooling immediately above a mold nanocavity after the polymer melt at $250{ }^{\circ} \mathrm{C}$ is brought in thermal contact with a metal mold insert or a HSQ/steel mold insert at $70{ }^{\circ} \mathrm{C}$. See figure 5 for drawings of the modeled melt/mold configurations.

Figure 5 shows the results of modeling the time-dependent spatial temperature distribution across the polymer/mold interface. The all-metal insert (figure 5a) gives rise to a sharp transition in temperature across the polymer/mold interface with the melt temperature reaching $100{ }^{\circ} \mathrm{C}\left(T_{\mathrm{g}}+20^{\circ} \mathrm{C}\right)$ after $10 \mu \mathrm{s}$ at a distance of $200 \mathrm{~nm}$ from the mold surface, i.e. half the nanopillar diameter in figure 2 . The temperature at the mold surface only increases slightly during this time, from $70{ }^{\circ} \mathrm{C}$ to $76{ }^{\circ} \mathrm{C}$. In contrast, the HSQ/steel mold insert (figure 5b) causes much slower cooling of the polymer melt with a polymer/HSQ interface temperature of $244{ }^{\circ} \mathrm{C}$ at $100 \mathrm{~ns}$ after initial contact and reaching $159{ }^{\circ} \mathrm{C}\left(T_{\mathrm{g}}+\right.$ $80{ }^{\circ} \mathrm{C}$ ) after $10 \mu \mathrm{s}$ at a distance of $200 \mathrm{~nm}$ from the mold surface. A temperature gradient arises across the HSQ film after $10 \mu \mathrm{s}$, with the outer surface being at $145{ }^{\circ} \mathrm{C}$ and the inner surface (towards stainless steel) being at $75^{\circ} \mathrm{C}$. After $1 \mathrm{~ms}$, the steel surface reaches a temperature of $79^{\circ} \mathrm{C}$. 

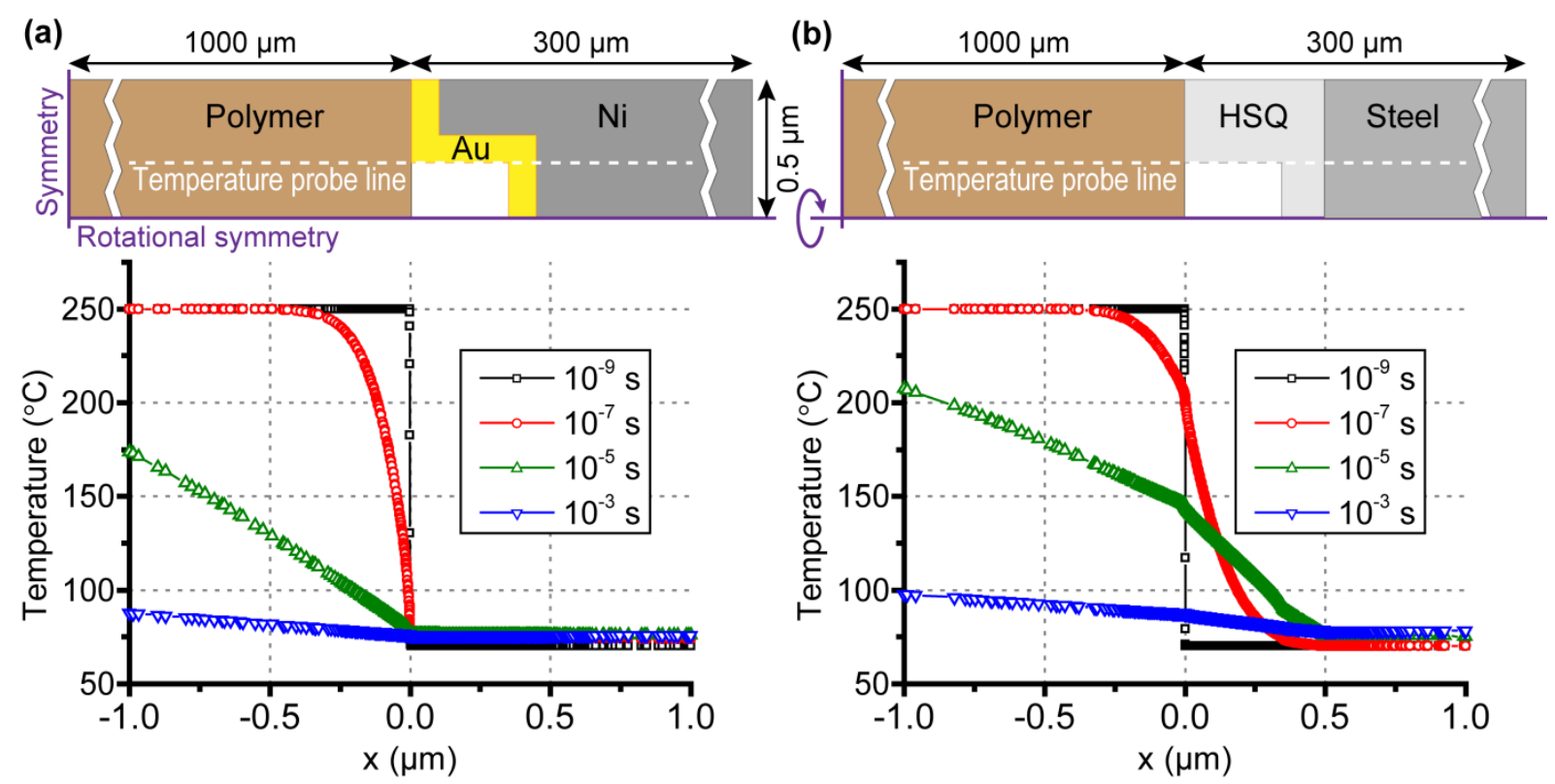

Figure 5. Finite element modeling (FEM) of the spatial temperature distribution across the polymer/mold interface $(\mathrm{x}=0)$ for an unfilled mold nanocavity at different time points for (a) allmetal mold inserts and (b) HSQ/steel mold inserts, both initially having $T_{\text {mold }}=70{ }^{\circ} \mathrm{C}$ and $T_{\text {melt }}=250$ ${ }^{\circ} \mathrm{C}$. The drawings in the upper row show the actual FEM models drawn to the scale of the simulation results shown in the lower row. The graphs show the temperatures measured at different simulation times along the dotted lines labeled "Temperature probe line". A rotational symmetry condition is applied to the lower horizontal boundary of each drawing (indicated by horizontal purple lines). A mirror symmetry condition is set for the leftmost vertical axis at a distance of $1000 \mu \mathrm{m}$ from the melt/mold interface (indicated by vertical purple lines), thereby modeling the $2 \mathrm{~mm}$ high physical mold cavity. The mold part extends for $300 \mu \mathrm{m}$ from the polymer/mold interface where a constant temperature condition of $70{ }^{\circ} \mathrm{C}$ is set.

\section{Discussion}

An imprinted HSQ film on a stainless steel mold insert significantly increases the replication quality of nanoscale features compared to a nickel mold insert fabricated by electroplating (figure 2 and 3 ). The replicated pillars are taller at all mold temperatures and with the difference being largest for $T_{\text {mold }}$ $=40{ }^{\circ} \mathrm{C}$ or $50{ }^{\circ} \mathrm{C}$, i.e. well below $T_{\mathrm{g}}$ of the polymer. Due to the lower thermal diffusivity of the HSQ film (table 2), heat transport across the polymer/mold surface is retarded. The melt is allowed to stay in a flowable state for a longer time and can therefore penetrate longer into the nanostructured holes before it solidifies. This is exemplied by the modeling results presented in figure 5 where a difference in melt temperature of $T_{\mathrm{g}}+20^{\circ} \mathrm{C}$ vs $T_{\mathrm{g}}+80^{\circ} \mathrm{C}$ on the all-metal mold vs HSQ/steel mold after $10 \mu \mathrm{s}$ corresponds to a reduction in melt flow viscosity by several orders of magnitude [49]. These findings agree well with previous literature on other heat-retarding mold materials. For instance, by using a nano-imprinted layer of SU-8 on a $740 \mu$ m polyimide (PI) sheet as a mold inlay, full replication of 100 
$\mathrm{nm}$ holes in polycarbonate (PC) with an aspect ratio of 1 was achieved at $T_{\text {mold }}=60{ }^{\circ} \mathrm{C}$ [39]. Injection molding using a Ni mold with the same surface pattern resulted in replicated pillars with only about $30 \%$ of the nominal height. Another study demonstrated replication of $1 \mu \mathrm{m}$ wide polymer gratings with an aspect ratio of 9 using a patterned polyurethane acrylate (PUA) layer on a $40 \mu \mathrm{m}$ thick polyethylene terephthalate (PET) film, although the replication quality was not uniform [38].

The non-uniform replication at low mold temperatures with an all-metal mold (figure 2 and table 3) may be explained by thermally induced flow instabilities that have previously been observed at low injection velocities and large differences between $T_{\text {melt }}$ and $T_{\text {mold }}$ (high cooling rates) [50]. With the onset of flow instability, the polymer solidifies before the cavity is completely filled, causing surface waviness with a periodicity of several micrometers. Flow instability is not observed to the same degree when using the HSQ-coated mold, and the surface topography is more uniformly replicated.

Numerical simulation of the heat transfer showed that the polymer melt close to the mold surface stays above $T_{\mathrm{g}}$ significantly longer for HSQ/stainless steel compared to a metal mold insert, due to the much lower thermal diffusivity. The initial temperatures for the $\mathrm{Ni} / \mathrm{COC}$ and the HSQ/COC as predicted by the simulations fit very weill with the analytical solution in equation 3 . The effect of viscous heat dissipation is not included in these simulations, and for replication of microstructures they have previously been assumed to be negligible [48]. We have assumed a perfect thermal contact between the melt and the mold surface. This is a reasonable approximation during the initial filling phase when the viscosity is low and thermal contraction of the bulk polymer melt is still minimal [51]. In the actual molding process, some thermal contact resistance will be observed due to the sparse interfacial contact between melt and mold at the atomic length scale at the low pressures present during early mold filling. The resistance could have been included in the model as a nanometer thick layer of reduced thermal conductivity. However, the exact thickness and thermal conductivity are difficult to assess and the resistance layer will due to its small thickness only act to retard the melt cooling slightly for both mold configurations so we have chosen to disregard this phenomenon in our semi-quantitative modeling. The polymer contracts during cooling, which is compensated by the holding pressure as long as polymer melt is allowed to move through the gate. After the gate is frozen, the cavity pressure drops and the polymer may separate from the mold due to continuous shrinking. Thus, a thermal contact resistance arises. However, as the replication of nanoscale features happens at a much shorter timescale, this is likely of less relevance for our study.

The actual filling time of a single nanocavity on the mold surface is very difficult to measure given the applied mold materials and the miniscule dimensions. A lower estimate on the filling time is given by the melt front velocity of $\sim 0.1 \mathrm{~m} / \mathrm{s}$ through the macroscopic mold cavity which corresponds to some microseconds for filling a $400 \mathrm{~nm}$ deep nanocavity at the mold surface. An upper estimate will be the time required for the outermost $400 \mathrm{~nm}$ of the polymer melt to approach the glass transition temperature which the simulations of both mold configurations predict to be in the millisecond range. For comparison with experimental observations, a prior study visually monitored the filling process 
into surface microgrooves of a nickel mold [52]. The authors reported that most of the filling of their $50 \mu \mathrm{m}$ or $100 \mu \mathrm{m}$ wide V-shaped microgrooves occurred within 1-2 ms of the initial pass of the polymer flow front depending on the injection velocity. The grooves of either width were only partly filled and the ultimate surface contour of the solified polymer material was equal for both groove widths. Both the fast millisecond scale structure formation and the shape equivalence in microgrooves of different widths is in agreement with our hypothesis of a fast sub-millisecond cooling dependent filling process of mold nanocavities.

Our observation of incomplete polymer filling on nanostructured $500 \mathrm{~nm}$ thick HSQ and a relatively long cycle time point to the need for further process optimization. Thicker HSQ films will most likely improve replication significantly, as the thermal resistance and thereby the cooling time and viscosity scales with the square of the mold material thickness. This is supported by additional thermal FEM studies with the geometry of figure $5 \mathrm{~b}$ showing a polymer melt temperature after $1 \mathrm{~ms}$ of contact at the melt/mold interface of $95{ }^{\circ} \mathrm{C}$ for a $1000 \mathrm{~nm}$ thick HSQ layer compared to $88{ }^{\circ} \mathrm{C}$ for a $500 \mathrm{~nm}$ thick HSQ layer (data not shown). However, thicker films also increase the risk of the film cracking or delaminating due to thermally induced stress between film and substrate. The use of 500 $\mathrm{nm}$ thick films in the present work is based on our prior experience with their ease of application and extreme robustness on steel supports. However, we also explored the application of thicker films in the micrometer range with good results after appropriate process optimization. Fast surface polymer cooling will be strongly retarded by a thicker HSQ coating, while slower bulk polymer cooling in the mold cavity will be almost unaffected so the process cycle time is not expected to be markedly increased. The main challenge in reducing the cycle time with the mold design used in this study is the wide sprue and the replica thickness of $2 \mathrm{~mm}$ that inherently requires long cooling times before demolding the replica below $T_{\mathrm{g}}$. Finite element modeling predicted that a change in replica thickness from $2 \mathrm{~mm}$ to $1 \mathrm{~mm}$ will reduce the time required for cooling the replica center to below $T_{\mathrm{g}}$ from $20 \mathrm{~s}$ to $5 \mathrm{~s}$ (data not shown). Further modeling showed that the use of either $500 \mathrm{~nm}$ or $1000 \mathrm{~nm}$ thick HSQ layers for replicating either $1 \mathrm{~mm}$ or $2 \mathrm{~mm}$ thick polymer replicas has no measurable influence on the time required for cooling the replica center below $T_{\mathrm{g}}$ (here $78^{\circ} \mathrm{C}$ for $\mathrm{COC}$ ) for a mold temperature of $T_{\mathrm{g}}-8^{\circ} \mathrm{C}$ (here $70^{\circ} \mathrm{C}$ ), as used in the current experimental and FEM studies (data not shown).

The materials used to demonstrate heat retardation in an injection molding process have so far mainly been polymer-based [53]. These materials are suitable for prototyping or small-volume productions. However, for large scale production they lack the wear resistance offered by those materials typically used in industry, such as tool steel. Thermally cured planar HSQ films have previously been used for injection molding [45] and for hot embossing [42], and we have recently observed minimum wear after injection molding >100 000 replicas on planar HSQ films (unpublished results). Above $400{ }^{\circ} \mathrm{C}$, the $\mathrm{Si}-\mathrm{H}$ bonds in the monomer dissociates and a cross-linked silica network forms, as previously reported and also verified by infrared spectroscopy in the current work (supplementary figure S1). The resulting silicon oxide network in the film is ceramic-like with a measured elastic modulus of $27.9 \mathrm{GPa}$ (supplementary figure S2) being smaller than fused silica (71.5 
GPa), nickel (200 GPa), and tool steel (180-200 GPa) but much higher than polymer mold materials (2-4 GPa) used in prior work. This ceramic-like coating is highly scratch resistant and is a robust candidate for mold coatings.

Another advantage of using HSQ as a heat-retarding mold coating is its ability to reduce surface roughness of the mold due to its high flowability, an important factor for the production of optically smooth polymer replica [45]. In addition, HSQ was shown to be fully compatible with silane surface chemistry. Thus, an anti-stiction coating like FDTS can be applied without any intermediate process steps. This is an important finding as a strong adhesion between polymer and mold can lead to incomplete replication or in worst case damage to the mold surface $[19,42]$.

\section{Conclusion}

We have demonstrated that replication is improved with a HSQ-coated steel mold compared to an all-metal mold formed by sputtering and electroplating, both in terms of a larger mean height and more uniformly distributed heights of pillars in the polymer. In contrast to the rapid formation of skin layers caused by the high cooling rates during isothermal molding, the HSQ film acts as a thermally insulating layer that allows more time for the melt to flow before solidifying. Furthermore, a dense anti-sticking monolayer can be applied directly to the thermally cured HSQ by a vapor deposition process to improve release of the polymer replica. In addition, the coated films have demonstrated sufficient durability for high volume fabrication processes. Thus, HSQ-coatings have the potential to improve nanoscale replication in industrially relevant settings by reducing the need for variotherm mold cycling.

\section{Acknowledgements}

This work was supported by the Danish Council for Strategic Research through the Strategic Research Center PolyNano (grant no 10-092322/DSF). We would like to thank Matthias Keil and Elena Khomtchenko at DTU Danchip for performing the DUV lithographic patterning of the silicon masters, and Jørgen Garnæs at the Danish National Metrology Institute for performing the nanoindentation studies.

\section{References}

[1] Giboz J, Copponnex T and Mélé P 2007 Microinjection molding of thermoplastic polymers: a review J. Micromech. Microeng. 17 R96-109

[2] Yang C, Yin X-H and Cheng G-M 2013 Microinjection molding of microsystem components: new aspects in improving performance J. Micromech. Microeng. 23093001

[3] Becker H and Gärtner C 2008 Polymer microfabrication technologies for microfluidic systems. Anal. Bioanal. Chem. 390 89-111 
[4] Attia U M, Marson S and Alcock J R 2009 Micro-injection moulding of polymer microfluidic devices Microfluid. Nanofluid. 7 1-28

[5] Gale M T 1997 Replication techniques for diffractive optical elements Microelectron. Eng. 34 $321-39$

[6] Ting C-J, Chang F-Y, Chen C-F and Chou C P 2008 Fabrication of an antireflective polymer optical film with subwavelength structures using a roll-to-roll micro-replication process $J$. Micromech. Microeng. 18075001

[7] Christiansen A B, Clausen J S, Mortensen N A and Kristensen A 2014 Injection moulding antireflective nanostructures Microelectron. Eng. 121 47-50

[8] Puukilainen E, Rasilainen T, Suvanto M and Pakkanen T A 2007 Superhydrophobic polyolefin surfaces: controlled micro- and nanostructures Langmuir 23 7263-8

[9] Huovinen E, Hirvi J, Suvanto M and Pakkanen T A 2012 Micro-micro hierarchy replacing micro-nano hierarchy: a precisely controlled way to produce wear-resistant superhydrophobic polymer surfaces Langmuir 28 14747-55

[10] Huovinen E, Takkunen L, Korpela T, Suvanto M, Pakkanen T T and Pakkanen T A 2014 Mechanically robust superhydrophobic polymer surfaces based on protective micropillars Langmuir 30 1435-43

[11] Dalby M J, Gadegaard N, Tare R, Andar A, Riehle M O, Herzyk P, Wilkinson C D W and Oreffo R O C 2007 The control of human mesenchymal cell differentiation using nanoscale symmetry and disorder Nat. Mater. 6 997-1003

[12] McMurray R J, Gadegaard N, Tsimbouri P M, Burgess K V, McNamara L E, Tare R, Murawski K, Kingham E, Oreffo R O C and Dalby M J 2011 Nanoscale surfaces for the longterm maintenance of mesenchymal stem cell phenotype and multipotency Nat. Mater. 10 63744

[13] Tsimbouri P, Gadegaard N, Burgess K, White K, Reynolds P, Herzyk P, Oreffo R and Dalby M J 2014 Nanotopographical effects on mesenchymal stem cell morphology and phenotype $J$. Cell. Biochem. 115 380-90

[14] Cha K J, Na M-H, Kim H W and Kim D S 2014 Nano Petri dishes: a new polystyrene platform for studying cell-nanoengineered surface interactions $J$. Micromech. Microeng. 24055002

[15] Macintyre D and Thoms S 1998 The fabrication of high resolution features by mould injection Microelectron. Eng. 41/42 211-4

[16] Schift H, David C, Gobrecht J, D’ Amore A, Simoneta D, Kaiser W and Gabriel M 2000 Quantitative analysis of the molding of nanostructures J. Vac. Sci. Technol. B 18 3564-8

[17] Schift H, David C, Gabriel M, Gobrecht J, Heyderman L, Kaiser W, Koppel S and Scandella L 2000 Nanoreplication in polymers using hot embossing and injection molding Microelectron. Eng. 53 171-4

[18] Gadegaard N, Mosler S and Larsen N B 2003 Biomimetic polymer nanostructures by injection molding Macromol. Mater. Eng. 288 76-83 
[19] Matschuk M and Larsen N B 2013 Injection molding of high aspect ratio sub-100 nm nanostructures J. Micromech. Microeng. 23025003

[20] Matschuk M, Bruus H and Larsen N B 2010 Nanostructures for all-polymer microfluidic systems Microelectron. Eng. 87 1379-82

[21] Viana J C 2004 Development of the skin layer in injection moulding: phenomenological model Polymer 45 993-1005

[22] Liou A-C and Chen R-H 2006 Injection molding of polymer micro- and sub-micron structures with high-aspect ratios Int. J. Adv. Manuf. Technol. 28 1097-103

[23] Mönkkönen K, Hietala J, Pääkkönen P, Pääkkönen E J, Kaikuranta T, Pakkanen T T and Jääskeläinen T 2002 Replication of sub-micron features using amorphous thermoplastics Polym. Eng. Sci. 42 1600-8

[24] Gornik C 2004 Injection moulding of parts with microstructured surfaces for medical applications Macromol. Symp. 217 365-74

[25] Tseng S-C, Chen Y-C, Kuo C-L and Shew B-Y 2005 A study of integration of LIGA and MEDM technology on the microinjection molding of ink-jet printers' nozzle plates Microsyst. Technol. 12 116-9

[26] Kim Y, Choi Y and Kang S 2005 Replication of high density optical disc using injection mold with MEMS heater Microsyst. Technol. 11 464-9

[27] Xiao C-L and Huang H-X 2014 Multiobjective optimization design of heating system in electric heating rapid thermal cycling mold for yielding high gloss parts J. Appl. Polym. Sci. 13139976

[28] Wang G, Zhao G and Guan Y 2013 Thermal response of an electric heating rapid heat cycle molding mold and its effect on surface appearance and tensile strength of the molded part $J$. Appl. Polym. Sci. 128 1339-52

[29] Park K and Lee S-I 2010 Localized mold heating with the aid of selective induction for injection molding of high aspect ratio micro-features J. Micromech. Microeng. 20035002

[30] Bekesi J, Kaakkunen J J J, Michaeli W, Klaiber F, Schoengart M, Ihlemann J and Simon P 2010 Fast fabrication of super-hydrophobic surfaces on polypropylene by replication of shortpulse laser structured molds Appl. Phys. A 99 691-5

[31] Chang P-C and Hwang S-J 2006 Experimental investigation of infrared rapid surface heating for injection molding J. Appl. Polym. Sci. 102 3704-13

[32] Lin H-Y, Chang C-H and Young W-B 2011 Experimental study on the filling of nano structures with infrared mold surface heating Int. Polym. Process. 26 73-81

[33] Liu J, Zhao G, Wang G and Guan Y 2011 Fully coupled transient heat transfer and melt filling simulations in rapid heat cycle molding with steam heating Polym. Plast. Technol. Eng. 50 423-37

[34] Michaeli W and Klaiber F 2009 Development of a system for laser-assisted molding of microand nanostructures J. Vac. Sci. Technol. B 27 1323-6 
[35] Lee J-S, Park K-W, Lee S-W, Kim J-H and Kim S 2003 Substrates for ultra small optical disks Optical Data Storage pp 228-30

[36] Inoue K, Hayashi K, Kawasaki Y and Ohno E 2003 Study on 40 Gbits/inch2 density molding using heat insulated mold Jpn. J. Appl. Phys. 42 774-5

[37] Schift H, Urwyler P and Kristiansen P M 2013 Surface-patterned micromechanical elements by polymer injection molding with hybrid molds J. Vac. Sci. Technol. B 31 06FD01

[38] Park S H, Lee W I, Moon S N, Yoo Y E and Cho Y H 2011 Injection molding micro patterns with high aspect ratio using a polymeric flexible stamper Express Polym. Lett. 5 950-8

[39] Stormonth-Darling J M and Gadegaard N 2012 Injection moulding difficult nanopatterns with hybrid polymer inlays Macromol. Mater. Eng. 297 1075-80

[40] Loboda M and Toskey G 1998 Understanding hydrogen silsesquioxane-based dielectric film processing Solid State Technol. 4199

[41] Yang J K W, Cord B, Duan H, Berggren K K, Klingfus J, Nam S-W, Kim K-B and Rooks M J 2009 Understanding of hydrogen silsesquioxane electron resist for sub-5-nm-half-pitch lithography J. Vac. Sci. Technol. B $272622-7$

[42] Gadegaard N and McCloy D 2007 Direct stamp fabrication for NIL and hot embossing using HSQ Microelectron. Eng. 84 2785-9

[43] Saleem M R, Stenberg P A, Khan M B, Khan Z M, Honkanen S and Turunen J 2012 Hydrogen silsesquioxane resist stamp for replication of nanophotonic components in polymers $J$. Micro/Nanolithogr., MEMS, MOEMS 11013007

[44] Cech J and Taboryski R 2012 Stability of FDTS monolayer coating on aluminum injection molding tools Appl. Surf. Sci. 259 538-41

[45] Cech J, Pranov H, Kofod G, Matschuk M, Murthy S and Taboryski R 2013 Surface roughness reduction using spray-coated hydrogen silsesquioxane reflow Appl. Surf. Sci. 280 424-30

[46] Loboda M, Grove C and Schneider R 1998 Properties of a-SiO[sub x]:H thin films deposited from hydrogen silsesquioxane resins J. Electrochem. Soc. 145 2861-6

[47] Liou H-C and Pretzer J 1998 Effect of curing temperature on the mechanical properties of hydrogen silsesquioxane thin films Thin Solid Films 335 186-91

[48] Tofteberg T R and Andreassen E 2010 Multiscale simulation of injection molding of parts with low aspect ratio microfeatures Int. Polym. Process. 25 63-74

[49] Jena R K, Chen X, Yue C Y and Lam Y C 2010 Viscosity of COC polymer (TOPAS) near the glass transition temperature: Experimental and modeling Polym. Test. 29 933-8

[50] Pranov H, Rasmussen H K, Larsen N B and Gadegaard N 2006 On the injection molding of nanostructured polymer surfaces Polym. Eng. Sci. 46 160-71

[51] Bendada A, Derdouri A, Lamontagne M and Simard Y 2004 Analysis of thermal contact resistance between polymer and mold in injection molding Appl. Therm. Eng. 24 2029-40 
[52] Yao D and Kim B 2002 Development of rapid heating and cooling systems for injection molding applications Polym. Eng. Sci. 42 2471-81

[53] Stormonth-Darling J M, Pedersen R H, How C and Gadegaard N 2014 Injection moulding of ultra high aspect ratio nanostructures using coated polymer tooling J. Micromech. Microeng. 24075019 